\title{
Development and Operation of a High Throughput Computer Hard Drive Recycling Enterprise
}

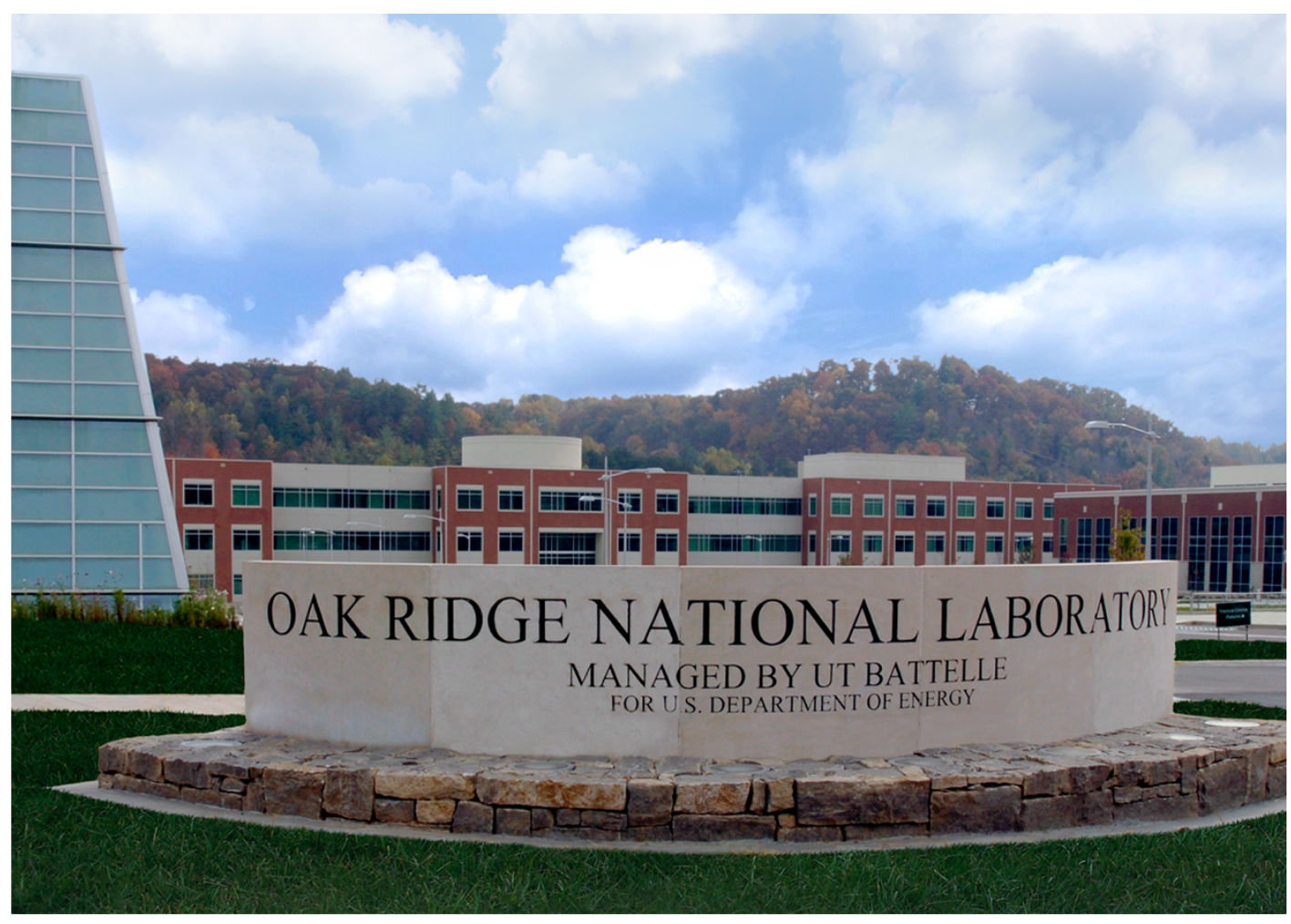

Approved for public release. Distribution is unlimited.
Timothy J. Mclntyre Jonathan J. Harter Thomas A. Roberts

November 2019 


\section{DOCUMENT AVAILABILITY}

Reports produced after January 1, 1996, are generally available free via US Department of Energy (DOE) SciTech Connect.

Website http://www.osti.gov/scitech/

Reports produced before January 1, 1996, may be purchased by members of the public from the following source:

National Technical Information Service

5285 Port Royal Road

Springfield, VA 22161

Telephone 703-605-6000 (1-800-553-6847)

TDD 703-487-4639

Fax 703-605-6900

E-mail info@ntis.gov

Website http://www.ntis.gov/help/ordermethods.aspx

Reports are available to DOE employees, DOE contractors, Energy Technology Data Exchange representatives, and International Nuclear Information System representatives from the following source:

Office of Scientific and Technical Information

PO Box 62

Oak Ridge, TN 37831

Telephone 865-576-8401

Fax 865-576-5728

E-mail reports@osti.gov

Website http://www.osti.gov/contact.html

This report was prepared as an account of work sponsored by an agency of the United States Government. Neither the United States Government nor any agency thereof, nor any of their employees, makes any warranty, express or implied, or assumes any legal liability or responsibility for the accuracy, completeness, or usefulness of any information, apparatus, product, or process disclosed, or represents that its use would not infringe privately owned rights. Reference herein to any specific commercial product, process, or service by trade name, trademark, manufacturer, or otherwise, does not necessarily constitute or imply its endorsement, recommendation, or favoring by the United States Government or any agency thereof. The views and opinions of authors expressed herein do not necessarily state or reflect those of the United States Government or any agency thereof. 
ORNL/TM-2019/1374

CRADA/NFE-16-05989

Electrical and Electronic Systems Research and Development

Development and Operation of a High Throughput Computer Hard Drive Recycling Enterprise

\author{
Timothy J. McIntyre \\ Jonathan J. Harter \\ Thomas A. Roberts
}

Date Published: November 2019

\author{
Prepared by \\ OAK RIDGE NATIONAL LABORATORY \\ Oak Ridge, Tennessee 37831-6283 \\ managed by \\ UT-BATTELLE, LLC \\ for the \\ US DEPARTMENT OF ENERGY \\ under contract DE-AC05-00OR22725
}

Approved for Public Release 



\begin{abstract}
The aim of this collaborative effort is to develop, construct and operate a high throughput computer hard disc drive (HDD) recycling system.

Research conducted as part of the Critical Materials Institute (CMI), a Department of Energy (DOE) Energy Innovation Hub, has revealed the economic rationale and the necessary technology for a potentially viable HDD recycling enterprise. Moreover, the very notion of CMI is the development of replacement sources of rare earth critical materials that enable the U.S. to become less dependent on single source supplies. Focused on end-of-life (EOL) consumer products containing rare earth permanent magnets, this cooperative endeavor will develop, construct and operate a highly automated recycling process. Demonstrating economically viable recycling of high value products is largely an untapped resource in the U.S. Recycling HDDs to recover rare earth magnets and other valuable materials (e.g. aluminum, steel, printed circuit boards, copper, etc.) presents a new opportunity to satisfy U.S. demand for highly desirable commodities.

The goal of this cooperative research and development agreement (CRADA) project is to create a commercial HDD recycling enterprise that changes the landscape of rare earth magnet material and magnet availability for U.S. manufacturers. Underpinning this primary goal is the development and demonstration of an economic HDD recycling process that provides a significant and alternative supply of rare earth magnets that is not dependent upon foreign sourcing. Oak Ridge National Laboratory (ORNL) has researched the technology options and down selected specific sub-process technologies based upon throughput and economic potential. The participant, however, brings significant process design, development and operational experience that may results in process improvement or optimization strategies that will be explored in collaboration with the contractor.

The final outcome of this CRADA is a system/process for recycling large quantities of HDDs. The technology is available for commercial scale-up.
\end{abstract}




\section{Statement of Objectives}

The objective of this cooperative agreement is development, construction and operation of a high throughput HDD recycling pilot line. Development of technology to successfully accomplish this goal has been carried-out according to the following tasks.

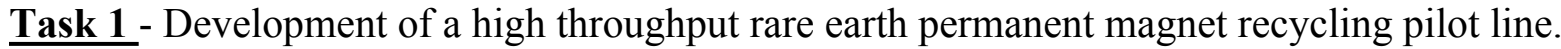

Conceptual designs of discrete process steps developed by ORNL will be integrated into a continuous, high throughput system. Collaborating with the CRADA partner to jointly develop processing targets and investigate system-level requirements will define a commercially viable design and development process for high throughput rare earth permanent magnet recovery from decommissioned computer hard disk drives (HDDs).

The collaboration team will execute the following activities as the scope of work for task 1 .

- Identify opportunities for industrial automation and tooling technologies to enable the most cost effective and high throughput magnet recovery from HDDs;

- Determine preferred design features that optimize deployment, operation and maintenance;

- Research special tooling, methods, control algorithms, etc. to optimize process efficiency;

- Develop prototype sub-system designs and algorithms to accomplish efficient recovery;

- Research the functionality and interoperability of prototype sub-system designs;

- Evaluate current state of the art technologies and approaches;

- Identify facilities for the construction and operation of the prototype processing line;

- Design, develop and test commercial-scale automation concepts to meet high throughput targets;

- Evaluate and document prototype performance related requirements for reliable HDD processing; and

- Develop a test plan to verify functionality and validate performance targets.

Task 2 - Develop and construct prototype automated HDD recycling system

The CRADA partners will jointly develop the strategy for commercial operation of an HDD recycling enterprise by completing the following tasks.

- Review any background intellectual property that could be leveraged to complete this task;

- Review research results and engineering trade-off studies related to automated HDD recycling system design;

- Develop economic analyses that demonstrate commercial viability of the process design;

- Procure necessary hardware and develop unique hardware and software to operate system equipment;

- The CRADA partner will contribute manufacturing process and tooling design expertise for prototype system design, development and operation;

- Construct and operate the prototype system at partner's location; and

- Execute the test plan to evaluate performance and identify process improvements. 


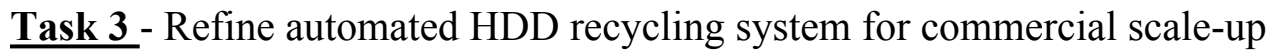

A design review among CRADA partners will be held to discuss:

1. Pilot line performance targets and potential corrective action plans;

2. Deployment strategies that transition ORNL conceptual designs to commercial-scale operations

3. Economic analyses developed to support scale-up; and

4. Identify process improvement opportunities and develop technology solutions to optimize system performance, such as uptime, throughput, maintenance, etc.

Benefits to the Funding DOE Office's Mission

This transformative technology development creates a completely new supply chain for critical materials. HDD value recovery technology reduces the carbon footprint of neodymium (Nd) by $>90 \%$ through mining end-of-life consumer products versus mining rocks. The high throughput processing technology developed by this CRADA is capable of processing $>10$ million HDDs per year, producing more than 200MT of neodymium oxide. Alternatively, directly processing recovered Nd into new magnets is also a viable option. The technologies explored during this CRADA include HDD dismantlement, punching the magnet assembly free from the remaining HDD and Nd recovery after HDD shredding. Research followed by detailed economic analysis show that dismantlement technology is the best processing option from an economic and environmental perspective, but also creates a significant new source of the critical material $\mathrm{Nd}$ for national security applications. Additionally, HDD dismantlement has shown that it is possible to directly reuse valuable HDD subcomponents, notably the voice coil magnet assembly.

\section{Technical Discussion of Work Performed}

Currently, HDDs are manufactured to industry standard dimensions, but that has not always been the case. They are generally rectangular in shape but vary in thickness. So-called 2.5 " and 3.5" laptop and desktop drives actually have quite different dimensions ( 4"x 2.65 " laptop; 5.5 "x 4 " desktop). Fortunately, the remaining 3 manufacturers produce their drives according to these industry standard dimensions. HDDs are manufactured in very large quantities and are scrupulously monitored for quality assurance. As such, HDDs are labeled with several barcodes that identify their make, model number, capacity, serial number, and other manufacturer information. For process development, HDDs are broken down into fields of view (FoV) surfaces from which data is collected. FoV include the top lid, inside with lid removed, voice coil pivot bearing, underside printed circuit board (PCB), and underside with PCB removed (Fig. 1). Small screws with heads ranging from $1 / 8$ " to $3 / 16$ " (Fig. 2) protrude above the surface to hold the sub-assemblies and components together. Collecting the precise coordinates of each fastener is needed for rapid and efficient dismantlement. These designs and tracking features can be used to guide a general HDD disassembly and magnet recycling process. Fastener locations are different for every hard drive model, thus presenting another challenge to be overcome by our system design and process. 


\section{Fields}

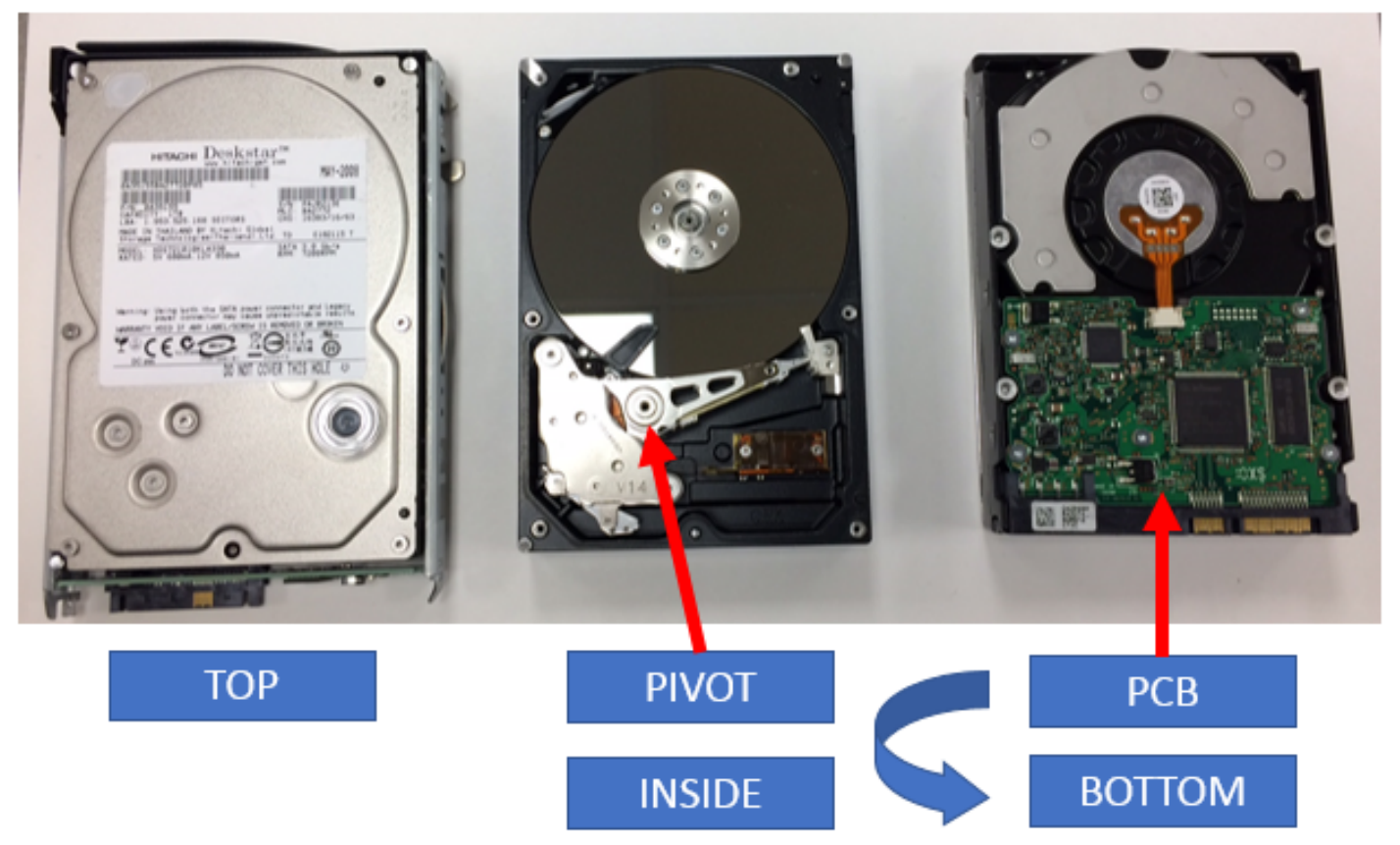

Flip

Figure 1. Hard disk drive fields of view (FoV).

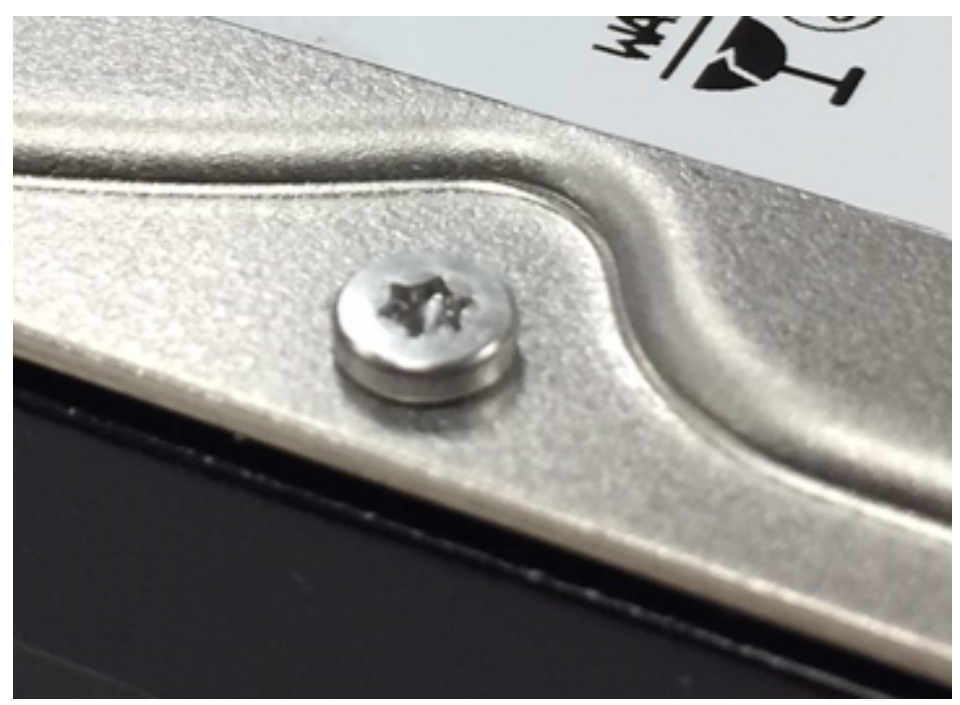

Figure 2. HDD lid Torx fastener.

Oak Ridge National Laboratory's (ORNL) rapid, autonomous HDD dismantlement process consists of the following steps: i) scan $\operatorname{HDD}(\mathrm{s})$ into inventory database; ii) sort; iii) align; iv) collect item barcode; v) rapid fastener removal OR divert to metrology station; and vi) collect separated value streams. Barcode scanning is used to track HDD movement through the process and chain of custody. Some HDDs will be diverted to a metrology process to create the FoV fastener maps needed for fastener removal. Each process communicates with a database (data structure loaded with HDD disassembly information) to record or receive information associated 
with HDD fastener locations and track process throughput. A data and material flowchart of the HDD dismantlement process is shown in Figure 3. One HDD every 4 seconds is the initial target disassembly and component recovery rate.

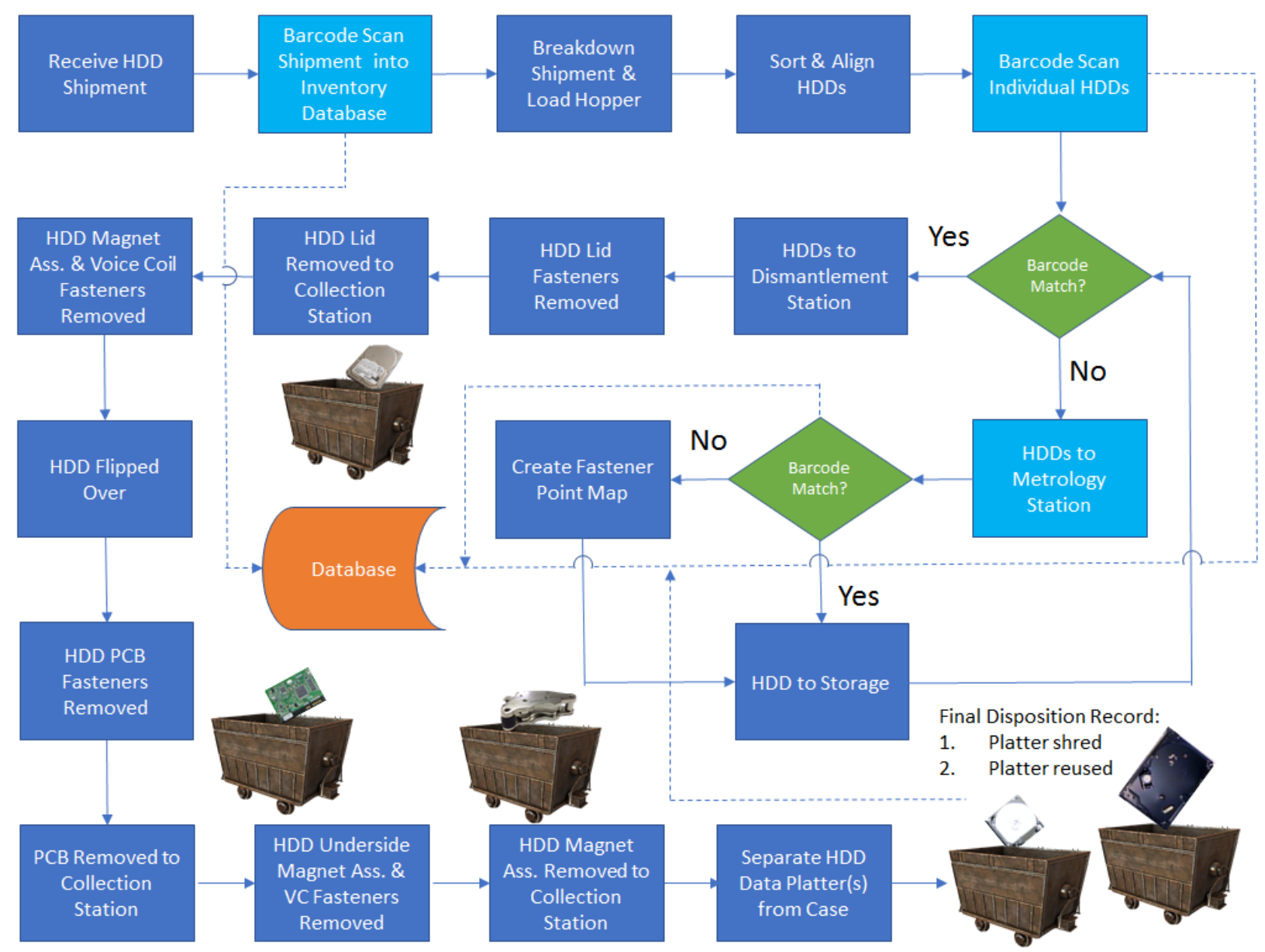

Figure 3. Proposed hard drive recycling program process flow chart.

\section{A. Populating the Database}

For each HDD to be processed, key information must first be collected. The data are stored within an online, machine accessible data architecture made up of tables containing different types of information needed for processing. The database is divided into three tables: inventory, barcodes, and points.

The inventory table is an appending tracking list of all HDDs scanned upon arrival and throughout the process. This table displays barcodes, timestamps, and location of the drive within the processing line. Keeping a record of every HDD barcode scan enables inventory tracking and provides accountability for customers, ensuring HDDs have been processed with the desired outcome. At this level, status of the HDD refers to the physical location of the HDD within the process (e.g. metrology station, storage, or at some stage of dismantlement). 


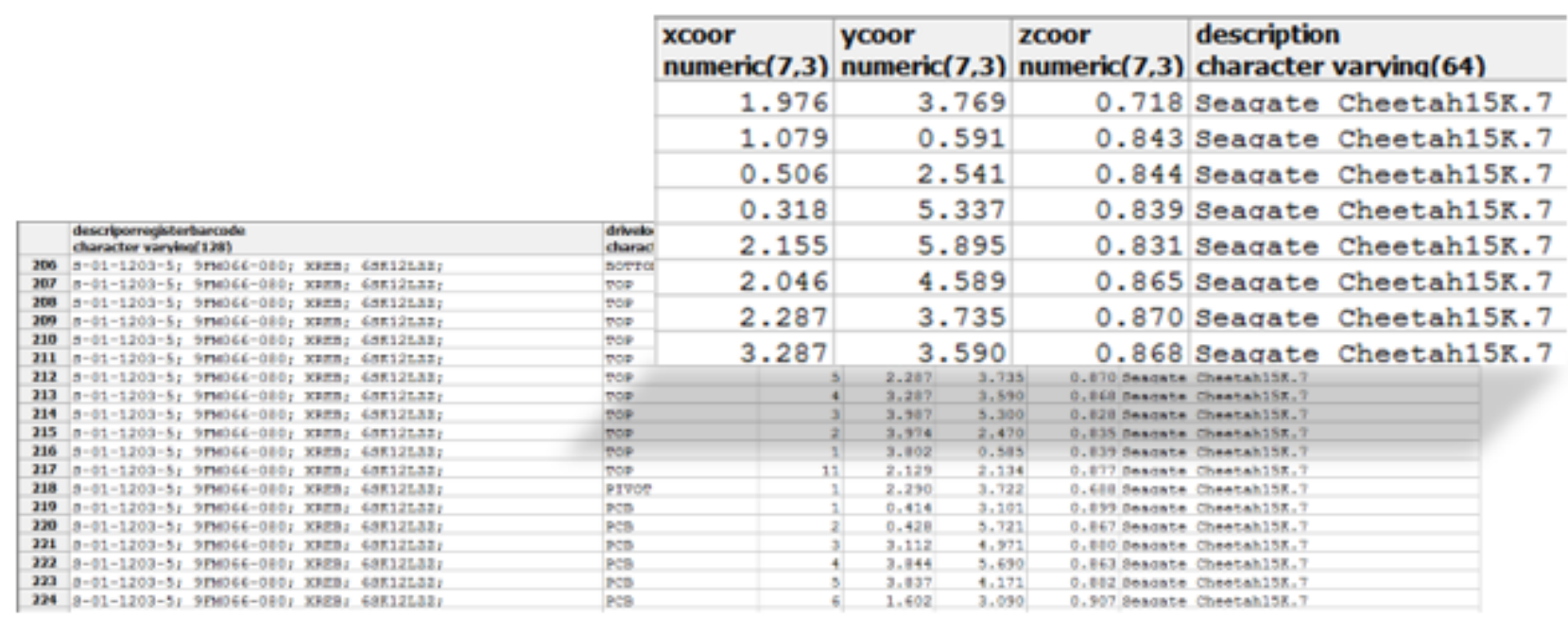

Figure 4. Excerpt from points table in database.

The barcodes table is a catalog of barcodes from each HDD label collected at the metrology station (described below). The table is referenced to sort incoming drives and provide a link to the points table. A drive is scanned upon arrival and categorized as recognized or unrecognized. Unrecognized drives are sent to metrology for information collection while recognized HDDs are distributed to processing lines or storage.

The points table is a collection of all fastener locations for each HDD model. Locations are recorded in Cartesian coordinates, referenced to a global origin $(X=0, Y=0, Z=0)$. Points in each FoV are used to create the tool path for ultrahigh speed milling machines. Figure 4 shows an excerpt from the points table displaying the $\mathrm{X}, \mathrm{Y}, \mathrm{Z}$ coordinates for each fastener of a Seagate Cheetah.

\section{B. Barcode Scanning}

A recycling program capable of handling millions of HDDs must include organization tools. Barcode scanners are strategically placed throughout the processing line, collecting data according to their location. The database is populated with data collected from several barcode scanner locations. Figure 5 shows the barcodes identified and logged by the system. 


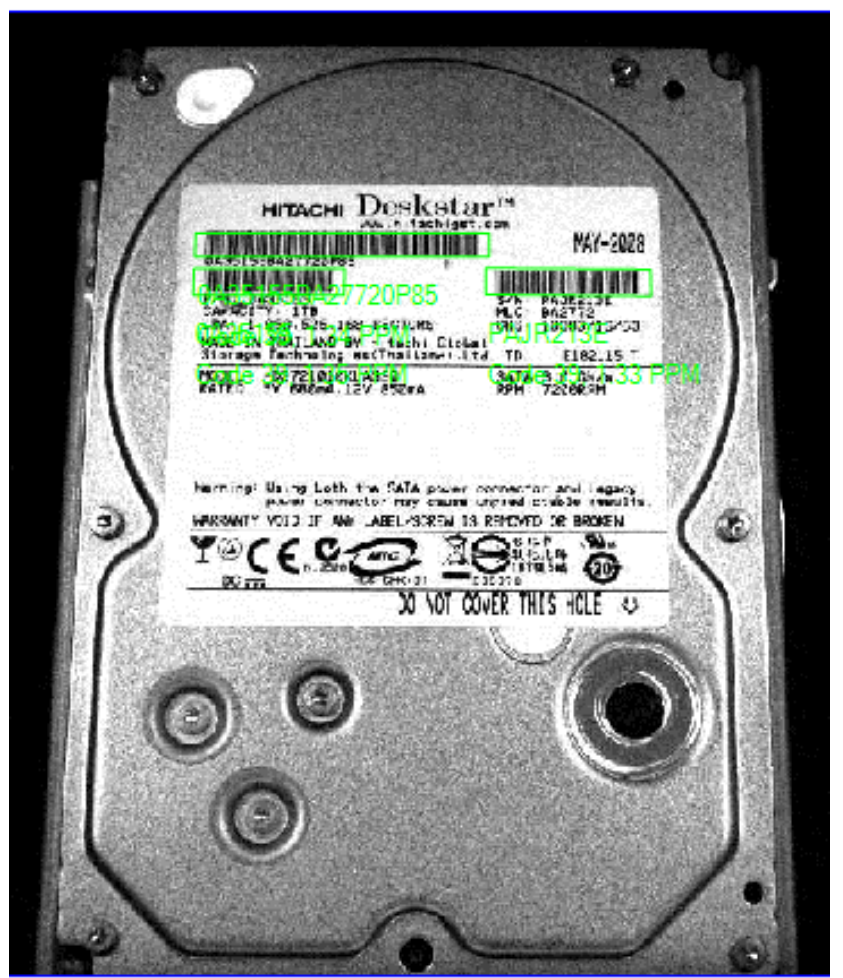

Figure 5. Multiple barcodes scanned from HDD label.

The Inventory scanner collects barcode data from every HDD entering the process. The inventory data is used to direct HDDs down the correct process pathway. If the HDD model barcode matches an existing record, the HDD is either sent to a short-term storage area or processed for dismantlement. If no matching record exists, the HDD is directed to the metrology station for data collection.

Upon arrival at the Metrology station, a barcode scanner scans the barcodes and creates a new metrology data collection record. The data collection record is then populated with precise X-Y$\mathrm{Z}$ coordinates for each fastener location of the particular HDD.

The Separation station barcode scanner reads barcodes and retrieves information from the points table created at the metrology station. Fastener locations are sent to robotic end mills for machining and dismantling.

\section{Metrology}

To achieve rapid dismantlement, predefined fastener locations (points) are used to control high speed milling robots. HDD information, such as barcodes and points, is collected by a technician. A Faro Arm, manually operated 3D coordinate measurement system (Fig. 6), is used to create point tables for fastener removal. The technician is prompted by a graphical user interface (GUI) to guide point collection. The GUI is an interactive LabView executable that allows the technician to visualize the point collection process. Metrology is a step-by-step process of scanning, naming the new database record, collecting points, and entering HDD data into the database. Metrology, on average, takes 3-5 minutes to complete all 8 steps listed below. 


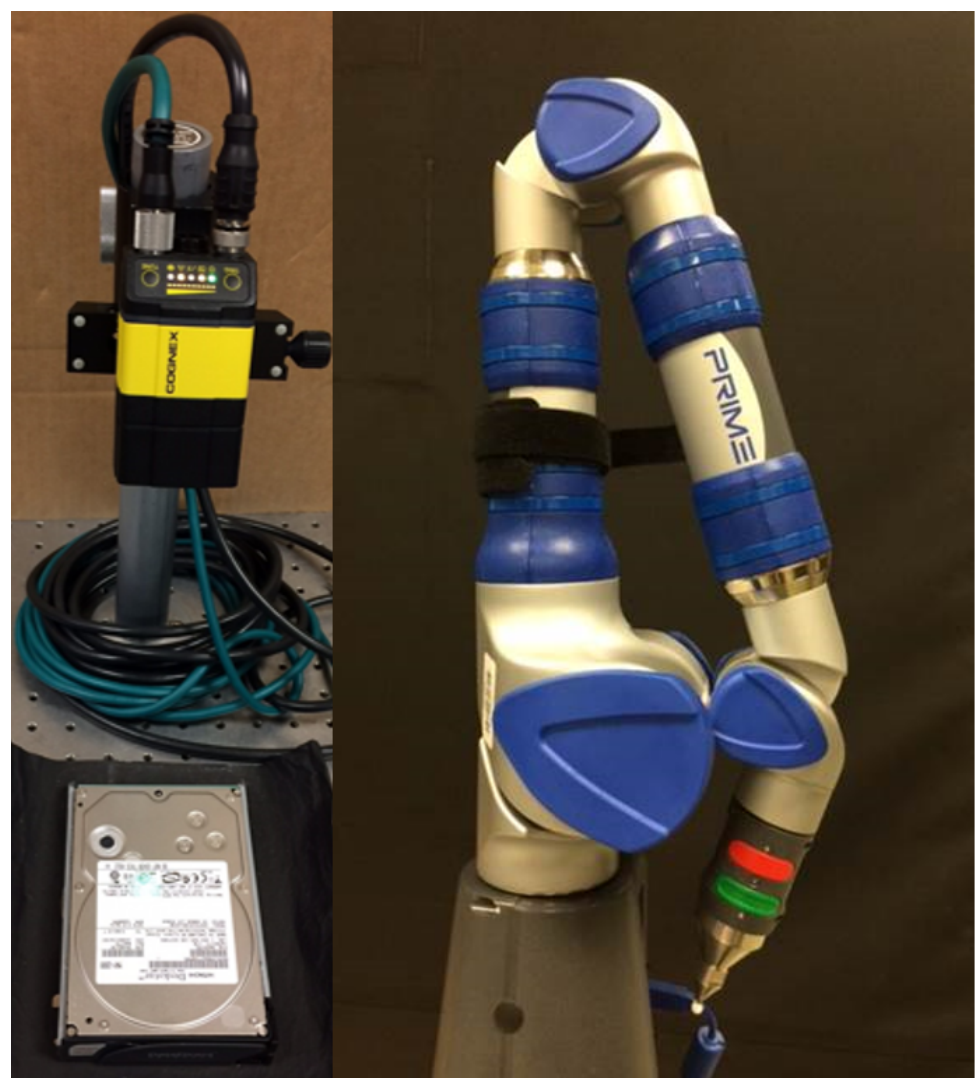

Figure 6. The metrology station uses a barcode scanner and Faro Arm 3D mapping system to create the fastener point map needed for dismantlement.

The current Metrology process is as follows:

- Step 1: Barcode scanner (Fig. 6) collects barcode data and verifies the HDD type has not previously been through metrology station.

- Step 2: Individual HDD types are uniquely identified by the following data format: (brand_model_capacity).

- Step 3: The technician uses the Faro Arm measurement system (Fig. 6) to precisely collect fastener locations.

Note: The Faro Arm coordinate measurement system is a robotic arm that has a ball probe on the end of the instrument to touch each fastener and precisely collect each X-Y-Z location (Fig.7). Each collected point is referenced to a fixed origin $(X=0, Y=0, Z=0)$, which is also the home position of the drill. Every fastener in each FoV is contacted by the probe to ensure all points needed for complete dismantlement are collected.

- Step 4: Removing the top lid reveals additional fasteners of interest (e.g. magnet assembly and voice coil pivot). After fastener location data are recorded, the HDD components of interest are removed to continue the data collection process.

- Step 5: Once components are removed, the HDD is flipped over to collect fastener location data on the printed circuit board (PCB).

- Step 6: With the PCB removed, fastener location data on the underside of the magnet assembly are collected. 


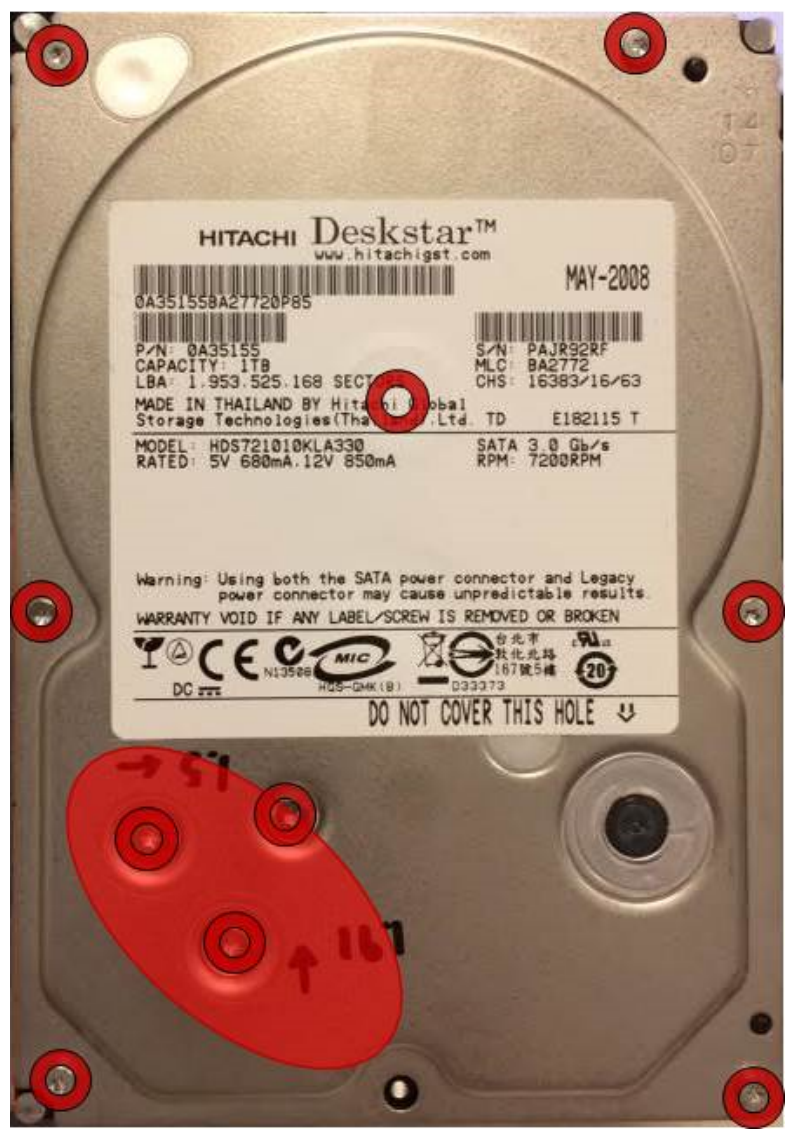

Figure 7. Fastener location map created by Faro Arm. Fastener locations are circled in red and the rare earth magnet assembly is located by the red oval.

- Step 7: A computer program is executed to combine collected points and barcodes. The program adds collected information to the online database.

- Step 8: The GUI resets to a refreshed LabView screen that is ready to step through the metrology process for the next HDD.

\section{Separation Process}

HDDs are dismantled by removing every fastener in each FoV. Each separated and recovered component represents a recovery stream with greater value than mixed metal waste created by shredding, according interviews conducted with scrap deals and e-waste processors. Collection of non-critical (e.g. non-rare earth elements) constituents such as copper, nickel, aluminum, steel, and various precious metals embedded in $\mathrm{PCBs}$, helps offset construction and operating costs of the pilot line. Rather than shredding or mangling the HDD, our process allows components to be recovered undamaged. These unmixed recovery streams are sold to recyclers or can be reused in new items; a so-called circular economy. The dismantlement processing line consists of a feeding and alignment system, a pick-and-place robot, an indexing conveyor, fastener drilling station, and robots or actuators that perform separation and collection of components after fastener removal. 
Sorting and Alignment- The sorting and alignment system, or bowl feeder, acts to position the HDDs for maximum value recovery. An elevating conveyor feeds the HDDs into a large, vibrating bowl. The vibrating bowl is engineered to circulate HDDs through a series of static mechanical articulations that act to align the HDDs. These articulations flip and rotate the HDDs as needed for the desired alignment outcome. If an HDD is not properly aligned it is returned automatically to the bottom of the bowl for realignment (Fig.8).

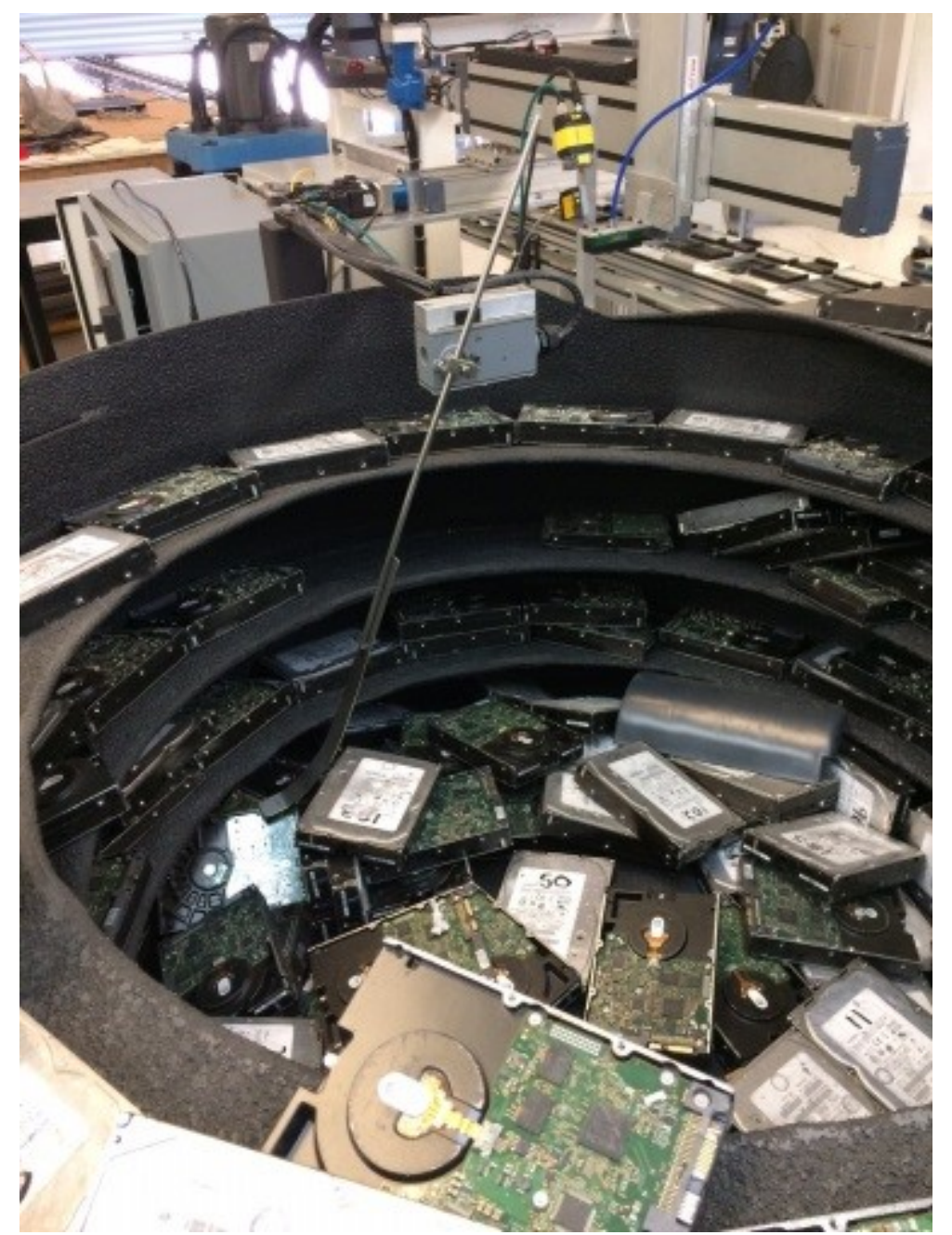

Figure 8. HDD bowl feeder alignment machine sorting HDDs.

Pick-and-Place Robot- Upon exiting the alignment system, HDDs are scanned in a first-in firstout (FIFO) sequence by the separation process barcode scanner. This initial barcode scan of a single HDD determines whether the HDD information has already been recorded in the database. Depending upon its status, HDDs are either queued for machining, sent to the metrology station, or placed in storage for future processing. The pick-and-place robot performs this sorting task (Fig.9). 


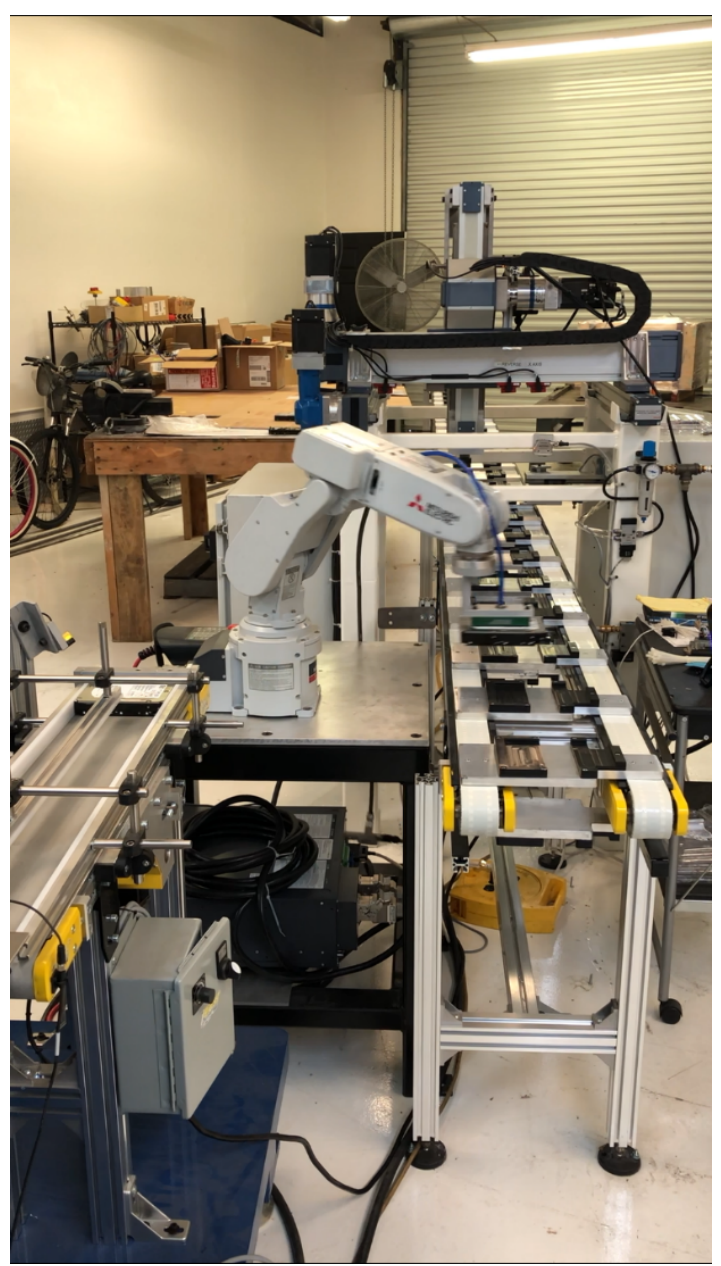

Figure 9. Hard disk drive dismantlement pilot demonstrating pick-and-place robot operation.

Indexing Conveyor- HDDs that are directed for machining are picked from the bowl feeder exit conveyor and placed on the indexing conveyor shown in Figure 9. The indexing conveyor is fixtured to repeatedly capture HDDs and place them precisely into the machining fixtures. As machining tasks are completed, the conveyor advances, or indexes each HDD by one increment for additional processing.

Machining Stations- A series of indexed operations including: i) HDD lid removal; ii) internal magnet assembly and voice coil pivot fastener removal; iii) HDD flip; iv) PCB fastener removal; and v) lower magnet assembly fastener removal, are performed by high speed robots functionalized for drilling. Each machining operation is completed in 10 seconds or less, enabling high throughput dismantlement. 


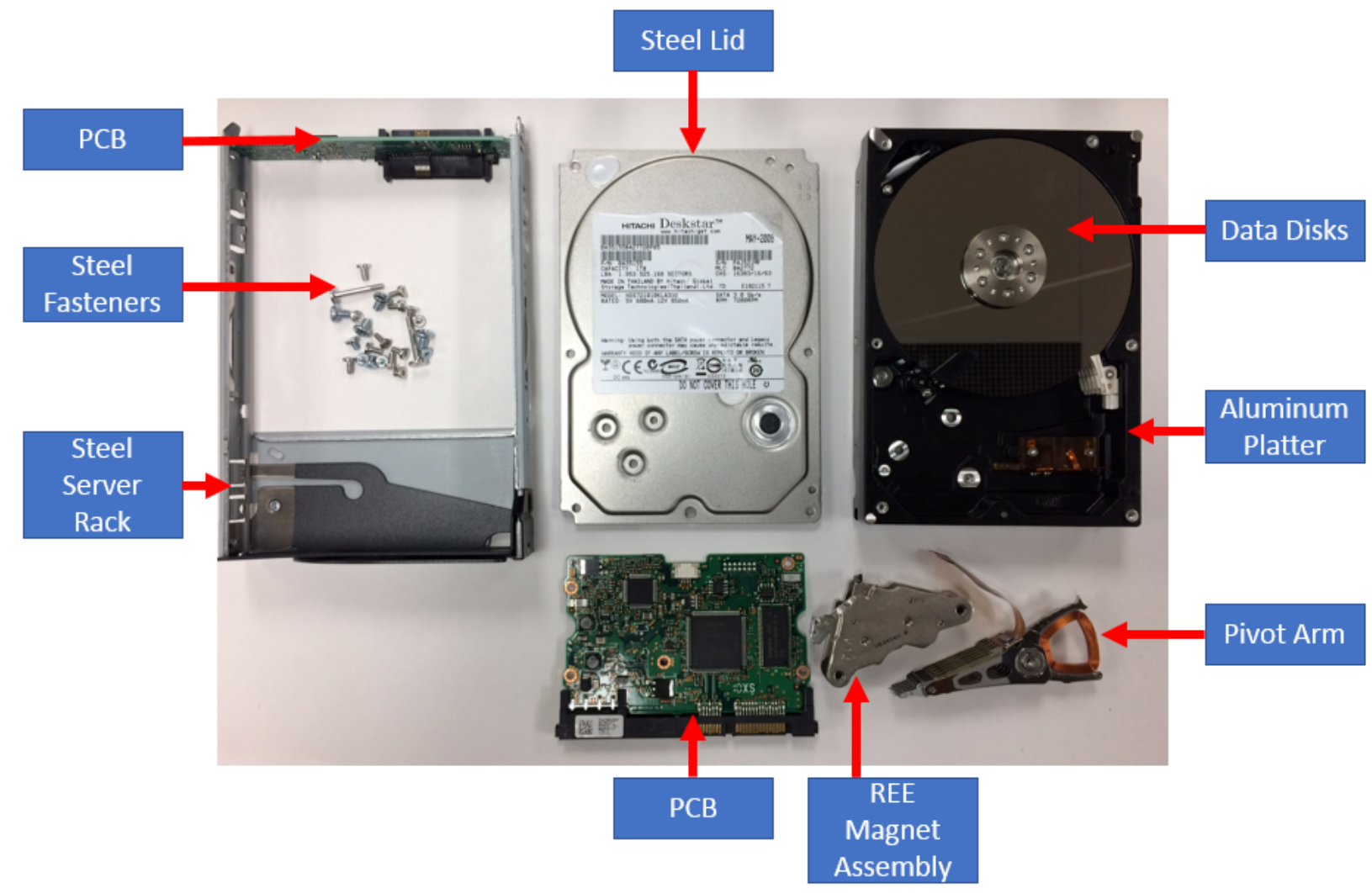

Figure 10. Dismantled HDD from dismantlement procedure.

Component Collection Robots and Actuators- A component collection robot performs the task of pulling the HDD lid free from the case after the fasteners are machined. Other HDD manipulation tasks include flipping the HDD for machining tasks on the underside and collecting the PCB and magnet assembly. All these tasks and the information collection, processing, storage and communication are coordinated by programmable logic controllers (PLC).

Figure 10 shows a dismantled HDD with at least four value streams including: steel, aluminum, PCBs and magnet assemblies. Further separation of recovered components can be performed, liberating copper, permalloy/mu-metal and data platters for potential direct reuse. Magnet assemblies (Fig. 11) are of particular interest to HDD manufactures. In one case, the CEO of an HDD manufacturer has challenged the HDD design team to make new HDDs from old HDDs. Recertifying the magnet assemblies is a critical early step. Magnet material in addition to magnet assemblies are valuable for other consumers interested in the raw elements. A magnet assembly, magnet removal process is being developed. Furthermore, a neodymium separation process is also being developed. 


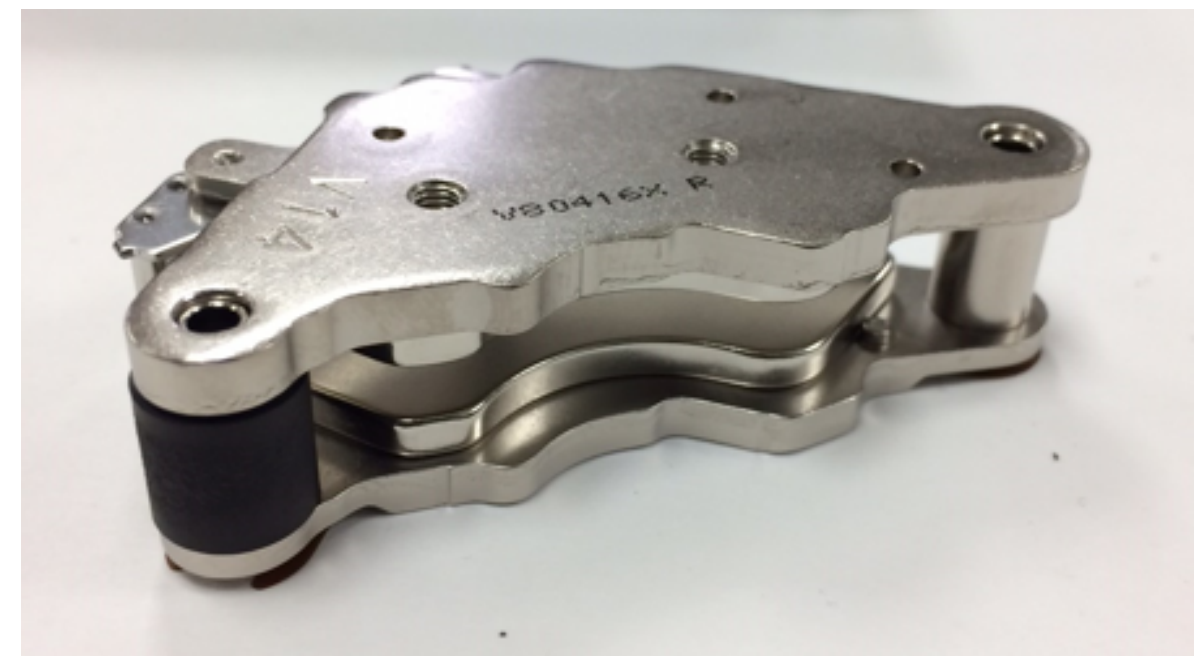

Figure 11. Extracted magnet assembly from enterprise HDD containing approximately 22.0 grams of Nd-Fe-B.

\section{A. Recovering Critical Materials from Other Manufactured Items}

HDDs are just one of many mass-produced items that contain REEs. Electric and hybrid electric vehicle traction drive motors and generators contain significant quantities of REEs. Electric vehicle (EV) motors contain internal permanent magnet rotors (IPMR) with large amounts of embedded Nd-Fe-B magnets. Nearly $3.4 \mathrm{~kg}$ (7.5 pounds) of rare-earth magnets have been recovered from a single motor during preliminary dismantlement research. We anticipate that disassembling EV motors will be similar to processing HDDs; fastener locations will be collected, stored, and used by robots for automated dismantlement. Currently, EVs and hybrid electric vehicles are increasing in popularity, but few have reached end of life. EV motors have a limited life span and quantities of end-of-life EV/HEV motors are expected to grow rapidly over the next decade. There are other REE containing motors in vehicles beside traction motors.

Starter motors, power accessory motors, and stereo loudspeakers are additional items containing permanent magnets. Other significant sources of REEs include pumps, fans, mixers, generators, and other rotating apparatus.

$\underline{\text { Invention Disclosures, Patents and Publications }}$

Two invention disclosures have been filed;

A. Hard Drive Dismantlement for Large Scale Recovery of Rare Earth Permanent Magnets. One publication, same title as above.

Commercialization Potential

The CRADA partner is still engaged and recent developments with information technology (IT) asset management companies look very processing. The key hurdles to overcome are data security, long-term sources of HDD supplies and supplies at a scale large enough to engage large data center players.

Plans for Future Collaboration

As mentioned above, there are potentially very large supplies of HDDs to process. But most HDDs that are not refurbished and resold are shredded for data security reasons. We are actively 
seeking joint venture relationships with IT asset managers and data center operators. A direct reuse partnership with Seagate has already been identified.

\section{Conclusions}

Permanent magnets and the REE materials they contain are in increasingly high demand. Supply disruption is a real and present risk. Mining operations that have been mothballed are expensive and time-consuming to restart. While recovery from HDDs can produce 500 to perhaps 1,000 metric tons of Nd-Fe-B, that is but a small dent in world demand (26-30,000MT/yr.). CMI has recognized and attacked this challenge by developing recovery and recycling technologies that will be coming on-line at commercial scale in the next decade. More needs to be done to establish a circular economy culture in the United States that takes full advantage of a large opportunity presented by end-of-life product recycling. The objective of the dismantlement process is threefold: i) maximize value recovery; ii) create a new supply of REEs, in this case, neodymium; and iii) enable a circular economy by making available HDD components and subassemblies for direct reuse in new HDDs or elsewhere.

Efforts on high throughput recovery from HDDs will continue. HDD dismantlement has progressed to the pilot scale and will soon be scaled-up to process millions of HDDs/yr. Many HDDs are shredded for data security. This process is capable of extracting the data-containing platters that can be shredded aside from the other components. Looking ahead, a process capable of recovering $>95 \%$ of the REE content after shredding is also being developed. Furthermore, a highspeed punching process is also being studied as a means of recovering REEs as rapidly and inexpensively as possible.

Work will also continue on economic recovery of REEs from electric machines. Expanding beyond EV/HEV traction motors will be a challenge because motors are difficult to access in large quantities economically. Decommissioned wind turbines, audio speakers, electric bicycles, power tools and other consumer products contain RE permanent magnets. However, REE magnet recovery from these active electric devices may become much more economically favorable when combined with Li-ion battery recycling. 